\title{
Climate, disaster and risk: introduction
}

\author{
Simon Goldhill and Georgie Fitzgibbon
}

Abstract: This special issue focuses on the intersections of climate, disasters, and development. The research presented here is designed to facilitate climate-resilient decision-making, and promote sustainable development by maximising the beneficial impacts of responses to climate change and minimising negative impacts across the full spectrum of geographies and sectors that are potentially affected by the changing climate.

Keywords: Disaster, Risk, Sustainable Development, Logistics, Shelter, Vulnerability, Resilience, Infrastructure

Notes on the authors: Simon Goldhill is Professor of Greek at the University of Cambridge, and a Fellow of King's College, Cambridge. He was elected a Fellow of the British Academy in 2016, and currently serves as Foreign Secretary and Vice-President of the British Academy.

Dr Georgie Fitzgibbon is International Policy Adviser at the British Academy.

(C) The author(s) 2021. This is an open access article licensed under a

Creative Commons Attribution-NonCommercial-NoDerivs 4.0 Unported License 
This special issue focuses on the intersections of climate, disasters and development. The research presented here is designed to facilitate climate-resilient decision-making, and promote sustainable development by maximising the beneficial impacts of responses to climate change and minimising negative impacts across the full spectrum of geographies and sectors that are potentially affected by the changing climate.

In the first article John Twigg (2021) explores the evolution of shelter 'self-recovery'. Providing adequate shelter after disasters is often a huge challenge to humanitarian agencies, whose interventions may reach only a small proportion of affected households. To overcome this problem, the international humanitarian shelter sector is increasingly adopting what is called a 'self-recovery' approach that gives much greater choice and agency to disaster-affected households regarding their recovery pathways. This article reviews the concept of 'self-recovery', its application to housing reconstruction after disasters and the factors influencing its recent rise to prominence in humanitarian policy and practice. The article draws on academic studies, evidence generated by humanitarian agencies and the author's involvement as observer and participant in recent self-recovery initiatives.

The next article examines two experiences that have aimed to incorporate vulnerability concerns into the planning and optimisation of humanitarian logistics operations. Douglas Alem (2021) argues that natural disasters and the vulnerability of a population go hand in hand. We cannot understand the level of a disaster without grasping the extent of people's vulnerability. But how can we ensure that humanitarian assistance is targeted at people's vulnerability when the lack of resources makes it impossible to support all those that need it? This study thus contributes to this line of research by enhancing our understanding of how we can 'put the reality of the most vulnerable people first'. The first example relies on a very popular composite indicator called Social Vulnerability Index (SoVI) to build enhanced response capacity in more vulnerable areas. The second example is built upon a poverty measure called FosterGreer-Thorbecke (FGT) to identify the groups that potentially need the most relief aid supply and to help devising allocation plans in compliance with people's income. These two models reveal that in most cases targeting more vulnerable areas increases their level of access to relief aid goods without greatly compromising the relief service levels of less vulnerable areas.

Continuing in this vein, Peter Sammonds, Mohammad Shamsudduha and Bayes Ahmed (2021) discuss the lessons that can be learned from Bangladesh's journey towards resilience. Globally, disasters from natural and anthropogenic hazards or humanitarian crises can reverse development gains and weaken resilience. In recent years, some countries have made significant progress towards building resilience to disaster risks, including those driven by the climate crisis. Bangladesh is a leading example as it is one of the most vulnerable countries because of its particular intense and multifaceted hazard risks from climate change. Today, however, the scale of 
loss of human life from both rapid and slow-onset disasters (e.g., cyclone, flood and drought) is significantly lower than in the 1970s. This remarkable achievement was made possible by independence and the government's proactive investment in development and societal changes through education, technologies, and reduction in poverty and inequalities. However, the climate crisis is threatening these development and disaster risk reduction gains. In addition, disaster displacement is a major challenge. The COVID-19 pandemic has unveiled both strengths and weaknesses in our societies. This article argues that disaster management plans need to adapt to the climate crisis and human displacement and reduce migrants' vulnerability while responding to infectious disease transmission.

In the penultimate article Robin Coningham and Lisa Lucero (2021) consider lessons that could be learned from past disasters. Narratives of lost cities and the exploration of ruins have captivated scholars and travellers for hundreds of years with explanations for their demise ranging from invasions to cataclysmic environmental events. This article explores three case studies to consider the impact of climate change, disaster and risk on urban infrastructure in the past, as well as to reflect on potential lessons of adaptation and resilience for modern cities and their inhabitants. The first examines the degree to which historic urban infrastructure can tell us about seismic adaptation in pre-modern Nepal, as well as recognising the increasing challenges to vernacular architecture from climate change. The second, focusing on Sri Lanka's Medieval cities in the North Central Province, examines the intricate relationship between the ancient city of Anuradhapura and its artificial hydraulic landscape, a relationship which saw resilience defeated by irreversibly engineered adaptation. The final example is drawn from the experience of another tropical society on the other side of the globe, the low-density urban forms of the Classic Maya of Central America, which offers different yet relevant insights into alternate urban lifeways, both ancient and contemporary. Focusing on issues of successful and unsuccessful adaptations in urban settings over an archaeological time range and evaluating how archaeologists and historians have explored and presented this evidence, we conclude by considering how archaeology and archaeologists can also play a greater role in future sustainable urban planning.

The final article is based on an 18-month British Academy funded project, which focused on the Canary Islands, in order to clarify the condition of documentation with regard to connections with West Africa, primarily with Senegal, which is described as the main origin of the migrants to the Canary Islands. With the collaboration of Italian and Spanish academics and the utilisation of Canarian data, Caroline Wilkinson and Maria Castaneyra-Ruiz (2021) interrogate the challenges associated with the identification of migrant victims off the coast of the Canary Islands through fostered networks in the Canary Islands and Senegal. Finally, the report presents craniofacial depiction/analysis as an alternative biological and biometric tool for Migrant Disaster 
Victim Identification (MDVI). This project did not involve the implementation of migrant identification, but this will hopefully be achieved through follow-up projects. The report ends with a summary of the current status and provides recommendations for future MDVI.

This issue forms part of the British Academy's COP26 series which aims to raise awareness of the importance of the humanities and the social sciences in understanding the complex human and social dimensions to environmental challenges and their solutions. The authors are drawn from a range of Academy programmes, including Cities and Infrastructures, which funds interdisciplinary research projects that address the challenge of creating and maintaining sustainable and resilient cities, with the aim of informing relevant policies and interventions in developing countries, BA/Leverhulme Small Research Grants, which support primary research across the humanities and social sciences, and Knowledge Frontiers, which aims to enable different communities of knowledge and practice to illustrate the significant added value of international and interdisciplinary collaboration.

\section{References}

Alem, D. (2021), 'Insights from Vulnerability-driven Optimisation for Humanitarian Logistics', Journal of the British Academy, 9(s8): 23-53. https://doi.org/10.5871/jba/009s8.023

Coningham, R. \& Lucero, L.J. (2021), 'Urban Infrastructure, Climate Change, Disaster and Risk: Lessons from the Past for the Future', Journal of the British Academy, 9(s8): 79-114. https://doi. org/10.5871/jba/009s8.079

Sammonds, P., Shamsudduha, M. \& Ahmed, B. (2021), 'Climate Change Driven Disaster Risks in Bangladesh and its Journey towards Resilience', Journal of the British Academy, 9(s8): 55-77. https://doi.org/10.5871/jba/009s8.055

Twigg, T. (2021), "The Evolution of Shelter "Self-recovery": Adapting Thinking and Practice for Post-disaster Resilience', Journal of the British Academy, 9(s8): 5-22. https://doi.org/10.5871/ $\mathrm{jba} / 009 \mathrm{~s} 8.005$

Wilkinson, C. \& Castaneyra-Ruiz, M. (2021), 'The Current Status of Migrant Disaster Victim Identification in the Canary Islands', Journal of the British Academy, 9(s8): 115-134. https://doi. org/10.5871/jba/009s8.115

To cite the article: Simon Goldhill and Georgie Fitzgibbon (2021), 'Climate, disaster and risk: introduction', Journal of the British Academy, 9(s8): 1-4.

DOI https://doi.org/10.5871/jba/009s8.001

Journal of the British Academy (ISSN 2052-7217) is published by

The British Academy, 10-11 Carlton House Terrace, London, SW1Y 5AH

www.thebritishacademy.ac.uk 